\title{
Decomposition pathways in age hardening of Ti-Al-N films
}

\author{
R. Rachbauer, ${ }^{1, \text { a) }}$ S. Massl, ${ }^{2,3}$ E. Stergar, ${ }^{1,4}$ D. Holec, ${ }^{1}$ D. Kiener, ${ }^{2,3}$ J. Keckes, ${ }^{2,3}$ \\ J. Patscheider, ${ }^{5}$ M. Stiefel, ${ }^{5}$ H. Leitner, ${ }^{1,6}$ and P. H. Mayrhofer ${ }^{1}$ \\ ${ }^{1}$ Department Physical Metallurgy and Materials Testing, Montanuniversität Leoben, Franz-Josef-Str. 18, \\ A-8700 Leoben, Austria \\ ${ }^{2}$ Erich Schmid Institute of Materials Science, Austrian Academy of Sciences, Jahnstr. 12, A-8700 Leoben, \\ Austria \\ ${ }^{3}$ Department Materials Physics, Montanuniversität Leoben, Franz-Josef-Str. 18, A-8700 Leoben, Austria \\ ${ }^{4}$ Department of Chemical Engineering, University of California, Santa Barbara, California 93106, USA \\ ${ }^{5}$ Laboratory for Nanoscale Materials Science, Swiss Federal Laboratories for Materials Science and \\ Technology, EMPA, Überlandstr. 129, CH-8600 Dübendorf, Switzerland \\ ${ }^{6}$ Christian Doppler Laboratory for Early Stages of Precipitation, Montanuniversität Leoben, \\ Franz-Josef-Str. 18, A-8700 Leoben, Austria
}

(Received 8 March 2011; accepted 12 June 2011; published online 25 July 2011)

\begin{abstract}
The ability to increase the thermal stability of protective coatings under work load gives rise to scientific and industrial interest in age hardening of complex nitride coating systems such as ceramic-like $\mathrm{Ti}_{1-x} \mathrm{Al}_{x} \mathrm{~N}$. However, the decomposition pathway of these systems from single-phase cubic to the thermodynamically stable binary nitrides (cubic TiN and wurtzite AlN), which are essential for age hardening, are not yet fully understood. In particular, the role of decomposition kinetics still requires more detailed investigation. In the present work, the combined effect of annealing time and temperature upon the nano-structural development of $\mathrm{Ti}_{0.46} \mathrm{Al}_{0.54} \mathrm{~N}$ thin films is studied, with a thermal exposure of either $1 \mathrm{~min}$ or $120 \mathrm{~min}$ in $100^{\circ} \mathrm{C}$ steps from $500{ }^{\circ} \mathrm{C}$ to $1400^{\circ} \mathrm{C}$. The impact of chemical changes at the atomic scale on the development of micro-strain and mechanical properties is studied by post-annealing investigations using X-ray diffraction, nanoindentation, 3D-atom probe tomography and high-resolution transmission electron microscopy. The results clearly demonstrate that the spinodal decomposition process, triggering the increase of micro-strain and hardness, although taking place throughout the entire volume, is enhanced at high diffusivity paths such as grain or column boundaries and followed within the grains. A $b$ initio calculations further show that the early stages of wurtzite AlN precipitation are connected with increased strain formation, which is in excellent agreement with experimental observations. (C) 2011 American Institute of Physics. [doi:10.1063/1.3610451]
\end{abstract}

\section{INTRODUCTION}

The combination of high hardness, good oxidation resistance and the possibility to tune the Ti/Al ratio and microstructure of $\mathrm{Ti}_{1-x} \mathrm{Al}_{x} \mathrm{~N}$ thin films in a wide range, e.g., by different deposition processes, makes $\mathrm{Ti}_{1-x} \mathrm{Al}_{x} \mathrm{~N}$ one of the most versatile protective hard coating materials for many applications and substrates. ${ }^{1}$ The major use as protection for drills, tools, dies, and molds benefits from the high thermal stability of $\mathrm{Ti}_{1-x} \mathrm{Al}_{x} \mathrm{~N}$, which is known to be strongly correlated with its microstructure and chemical composition. ${ }^{2}$ Due to typical substrate temperatures of $\sim 500{ }^{\circ} \mathrm{C}(\sim 0.2-0.3$ of the melting temperature), the atomic reassembly during condensation from the vapor phase is limited, which results in a meta-stable solid solution of $\mathrm{Ti}_{1-x} \mathrm{Al}_{x} \mathrm{~N}$. During common physical vapor deposition (PVD) processes, crystallization in the cubic (c) $\mathrm{NaCl}$ (B1) structure is usually found up to $\mathrm{Al}$ contents of the metallic sublattice $x \sim 0.6-0.7 .^{3,4}$ Higher Al contents favor the wurtzite (w) $\mathrm{ZnS}$ (B4) structure. The metastable phases obtained from these processes exhibit

\footnotetext{
a) Author to whom correspondence should be addressed. Electronic mail: richard.rachbauer@unileoben.ac.at.
}

a driving force for separation toward their stable constituents c-TiN and w-AlN, strongly scaling with the Al content. ${ }^{5-9}$

In common milling operations, the high thermal work load on the coated tools typically reaches temperatures in excess of $\sim 900^{\circ} \mathrm{C}$. This enables sufficient diffusion in the coating to induce the chemically driven isostructural decomposition of metastable $\mathrm{Ti}_{1-x} \mathrm{Al}_{x} \mathrm{~N}$ into TiN- and $\mathrm{AlN}-$ enriched domains. ${ }^{10}$ In many reports ${ }^{2,8,11-13}$ this effect is attributed to spinodal decomposition of the $c-\mathrm{Ti}_{1-x} \mathrm{Al}_{x} \mathrm{~N}$ matrix, resulting in age hardening of $\mathrm{Ti}_{1-x} \mathrm{Al}_{x} \mathrm{~N}$.

In addition to the chemical driving force (due to a positive mixing enthalpy over the whole composition range of $\mathrm{Ti}_{1-x} \mathrm{Al}_{x} \mathrm{~N}$ ), also the development of elastic strain energy and the formation of new interfaces have to be taken into account. ${ }^{12}$ Outside the spinodal range, $0.27<x<0.98^{9,15-17}$ at $900{ }^{\circ} \mathrm{C}$, precipitation by nucleation and growth is the dominating reaction for decomposition into c-TiN and $\mathrm{w}-\mathrm{AlN}$, while within the spinodal range the iso-structural decomposition (without nucleation barrier) to form TiN- and $\mathrm{AlN}$ enriched domains, is the favored pathway.

Although the influence of annealing temperature on the structural evolution of $\mathrm{Ti}_{1-x} \mathrm{Al}_{x} \mathrm{~N}$ thin films was investigated by computational $^{12,15,16,18,19}$ and experimental ${ }^{8,11,12,14}$ methods, a combinatorial description of the kinetics and decomposition 
pathway is of paramount importance. In the present study, a detailed analysis of the structural and chemical evolution of $c-\mathrm{Ti}_{1-x} \mathrm{Al}_{x} \mathrm{~N}$ thin films as a function of temperature and time is presented and related to the development of the mechanical and electrical properties. The assessment of coating structure by $\mathrm{X}$-ray diffraction (XRD) and high resolution transmission electron microscopy (HR-TEM) is combined with a chemical and morphological analysis using three-dimensional atom probe tomography (3D-APT) and correlated to nanoindentation and electrical resistivity experiments. Ab initio calculations were performed to facilitate the interpretation of the experimental findings. The present study aims to elucidate the phase development, especially the morphology of spinodal decomposition, of metastable single phase $\mathrm{c}-\mathrm{Ti}_{1-x} \mathrm{Al}_{x} \mathrm{~N}$ toward its stable constituents c-TiN and w-AlN.

\section{EXPERIMENTAL}

\section{A. General considerations}

Two different polycrystalline substrates, low alloy steel foil (thickness $0.2 \mathrm{~mm}$ ) and polycrystalline $\mathrm{Al}_{2} \mathrm{O}_{3}$ platelets $(20 \times 7 \times 0.5 \mathrm{~mm})$ were selected for the present investigations. The low alloy steel foil can easily be removed chemically to avoid substrate interference during time and temperature dependent 3D-APT, XRD and TEM studies, whereas the polycrystalline $\mathrm{Al}_{2} \mathrm{O}_{3}$ provides an ideal substrate for nanoindentation and resistivity measurements of the thin films. For the deposition of the $\mathrm{Ti}_{1-x} \mathrm{Al}_{x} \mathrm{~N}$ thin films a mixed $\mathrm{Ar} / \mathrm{N}_{2}$-plasma discharge and a $\mathrm{Ti}_{0.50} \mathrm{Al}_{0.50}$ target (Plansee $\mathrm{AG}, \varnothing 150 \times 5 \mathrm{~mm}$ ) were used in a lab-scale magnetron sputter deposition plant. For a more detailed description of the parameters used, see Ref. 20.

\section{B. Experimental details}

After deposition, both the free standing thin film powder (after chemical removal from the low alloy steel substrate) and the coating on $\mathrm{Al}_{2} \mathrm{O}_{3}$ were annealed in a vacuum furnace (HTM Reetz $\mathrm{GmbH}$, base pressure $<5 \times 10^{-4} \mathrm{~Pa}$ ) at different temperatures $\left(T_{\mathrm{a}}\right)$ from 500 to $1400^{\circ} \mathrm{C}$ in $100^{\circ} \mathrm{C}$ steps, with a heating rate of $20 \mathrm{~K} \mathrm{~min}^{-1}$ and a cooling rate of $50 \mathrm{~K} \mathrm{~min}^{-1}$, and subsequently measured at room temperature. The reason for this was to minimize structural changes during the cooling process from $T_{\mathrm{a}}$. The samples were kept at $T_{\mathrm{a}}$ for either $1 \mathrm{~min}$ or $120 \mathrm{~min}$. Subsequent to the annealing treatment, the electrical resistivity of the coatings on $\mathrm{Al}_{2} \mathrm{O}_{3}$ was determined by a Jandel four-point probe. In this measurement, a current of $900 \mu \mathrm{A}$ was used and the sample geometry corrected according to Refs. 21 and 22. For nanoindentation a UMIS nanoindenter, equipped with a Berkovich tip, was used. A plateau test ${ }^{23}$ was performed, with stepwise increasing load from 6 to $25 \mathrm{mN}$ for at minimum 20 indentations, which ensured that the indentation was contained within the upper $10 \%$ of the coating in order to minimize possible substrate interference. Structural analysis was made using X-ray diffraction with a Bruker D8 and $\mathrm{Cu}-\mathrm{K}_{\alpha}$ emission, applying Bragg-Brentano geometry for the powdered free standing film material and grazing incidence at $2^{\circ}$ incidence angle for coatings on $\mathrm{Al}_{2} \mathrm{O}_{3}$ substrates. Quantitative $\mathrm{XRD}$ data obtained from the powdered film material were first fitted using the PeakFIT ${ }^{\circledR}$ program, applying a Voigt-function for all distinguishable cubic and wurtzite peaks in the measured range between 30 to $85^{\circ}$, prior to a Williamson-Hall analysis. ${ }^{24}$ In preparation for TEM and EDX analysis (using a $\mathrm{C}_{\mathrm{s}}$-corrected JEOL $2100 \mathrm{~F}$ equipped with a Gatan energy dispersive X-ray spectrometer (EDX) and operated at $200 \mathrm{kV}$ ), plan-view samples were polished and ion-milled using Argon ions in a Gatan Precision Ion Polishing System (PIPS). EDX measurements from scanning electron microscopy (SEM) studies, using a Zeiss Evo 50, of the coatings on alumina as well as the TEM investigations indicate consistent values of $\sim 22.5 \pm 0.5$ at. $\%$ for $\mathrm{Ti}, \sim 26.5 \pm 0.5$ at. $\%$ for $\mathrm{Al}$ and $\sim 51 \pm 1$ at. $\%$ for $\mathrm{N}$. The coating composition normalized to 50 at. $\% \mathrm{~N}$ will therefore be referred as $\mathrm{Ti}_{0.46} \mathrm{Al}_{0.54} \mathrm{~N}$.

Atom probe tomography (3D-APT) enables sub-nanometer resolution in the measurement direction, ${ }^{25}$ and provides a quantitative morphological description of the material in three dimensions. Previous work $^{10,20,26}$ introduces this technique applying an Imago LEAP 3000X-HR to the field of hard coatings and discusses APT sample preparation, experimental parameters and limitations of the technique in more detail. The parameters utilized for the $a b$ initio calculations can be found in Ref. 27.

\section{RESULTS AND DISCUSSION}

\section{A. Structure and mechanical properties}

Comparative X-ray analysis of powdered coating samples and coatings on $\mathrm{Al}_{2} \mathrm{O}_{3}$ after annealing for 1 min at $T_{\mathrm{a}}$ is shown in Figs. 1(a) and 1(b), respectively. For simplicity only the XRD patterns after annealing at 900, 1000, 1100, and $1300^{\circ} \mathrm{C}$ are presented. The observed structural features, such as peak intensities and the formation of $\mathrm{w}-\mathrm{AlN}$, are in good agreement for both the powdered coating and the coating on substrate. A single phase cubic solid solution of $\mathrm{Ti}_{0.46} \mathrm{Al}_{0.54} \mathrm{~N}$, with cubic lattice parameter $a_{\mathrm{c}}=4.181 \AA$, is obtained from the powdered samples in the as deposited state. The samples maintain their single phase cubic structure with increasing $T_{\mathrm{a}}$ up to $\sim 1000^{\circ} \mathrm{C}$. For $T_{\mathrm{a}}$ between 900 and $1000^{\circ} \mathrm{C}$ an asymmetric peak broadening is observed, which can be interpreted as a sign of isostructural formation of

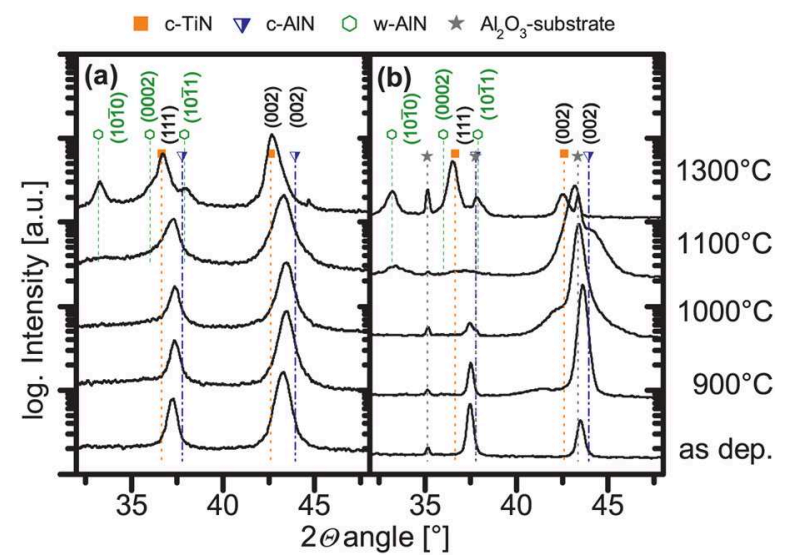

FIG. 1. (Color online) XRD pattern of annealed (a) $\mathrm{Ti}_{0.46} \mathrm{Al}_{0.54} \mathrm{~N}$ film powder and (b) $\mathrm{Ti}_{0.46} \mathrm{Al}_{0.54} \mathrm{~N}$ film on $\mathrm{Al}_{2} \mathrm{O}_{3}$ substrate. 
c-AlN- and c-TiN-rich domains. ${ }^{14}$ The variation of the cubic (111) and (002) peak intensities, visible predominantly in the $\mathrm{X}$-ray patterns of the films on $\mathrm{Al}_{2} \mathrm{O}_{3}$ substrate, is related to the strong elastic anisotropy in $\mathrm{Ti}_{1-x} \mathrm{Al}_{x} \mathrm{~N}$ solid solutions, which scales with the Al-content on the metallic sub-lattice. ${ }^{28}$ $\mathrm{Ti}_{1-x} \mathrm{Al}_{x} \mathrm{~N}$ with low $\mathrm{Al}$-contents is known to be stiffer in the (002) direction, whereas high $\mathrm{Al}$ contents exhibit a higher stiffness in (111) direction. Already for $x \geq 0.28$ the (002) direction exhibits a lower elastic modulus than the (111) direction. ${ }^{28}$ Therefore, to minimize strain energy (due to coherency between the cubic AlN-enriched domains, the remaining matrix and TiN-enriched areas) during spinodal decomposition, the orientation of the $\mathrm{Ti}_{0.46} \mathrm{Al}_{0.54} \mathrm{~N}$ coating will change toward (002). Assuming a higher strain level in the coating on $\mathrm{Al}_{2} \mathrm{O}_{3}$, stemming from the additional strain interaction with the substrate, results in pronounced peak intensities of the (002) reflexes, especially visible at $T_{\mathrm{a}}=1000$ and $1100{ }^{\circ} \mathrm{C}$, compared to the powdered film. This result correlates with substrate-induced compressive stresses in the films favoring the cubic phase in $\mathrm{Ti}_{1-x} \mathrm{Al}_{x} \mathrm{~N} .{ }^{29}$

The structural evolution of $\mathrm{c}-\mathrm{Ti}_{0.46} \mathrm{Al}_{0.54} \mathrm{~N}$ has a remarkable impact on the mechanical properties, presented in terms of the dependence of hardness $(H)$ and indentation modulus $(E)$ on $T_{\mathrm{a}}$ and $t_{\mathrm{a}}$ in Fig. 2. In good agreement with earlier studies, ${ }^{8,14} \mathrm{a}$ hardness increase of $\sim 25 \%$, from $26 \pm 2 \mathrm{GPa}$ in the as deposited state to $32.5 \pm 1.2 \mathrm{GPa}$ after annealing for $1 \mathrm{~min}$ at $1000^{\circ} \mathrm{C}$ is observed. Similarly the hardness increases when annealing at $T_{\mathrm{a}}$ for $t_{\mathrm{a}}=120 \mathrm{~min}$, although the peak hardness of $33.3 \pm 1.8 \mathrm{GPa}$ (an increase of $\sim 28 \%$ ) is obtained at a lower temperature of $800{ }^{\circ} \mathrm{C}$. For both annealing times, the hardness significantly decreases for $T_{\mathrm{a}}$ above the peak value, which is called overaging, ${ }^{30}$ whereby the hardness decline is slower for coatings annealed for $t_{\mathrm{a}}=120 \mathrm{~min}$. As previously reported ${ }^{8,14}$ the hardness decrease is connected with the formation of w-AlN; see for comparison Figs. 1 and 2. The behavior of the indentation moduli is similar, but especially for $t_{\mathrm{a}}=1 \min E$ first slightly decreases with $T_{\mathrm{a}}$ before the decomposition process initiates an

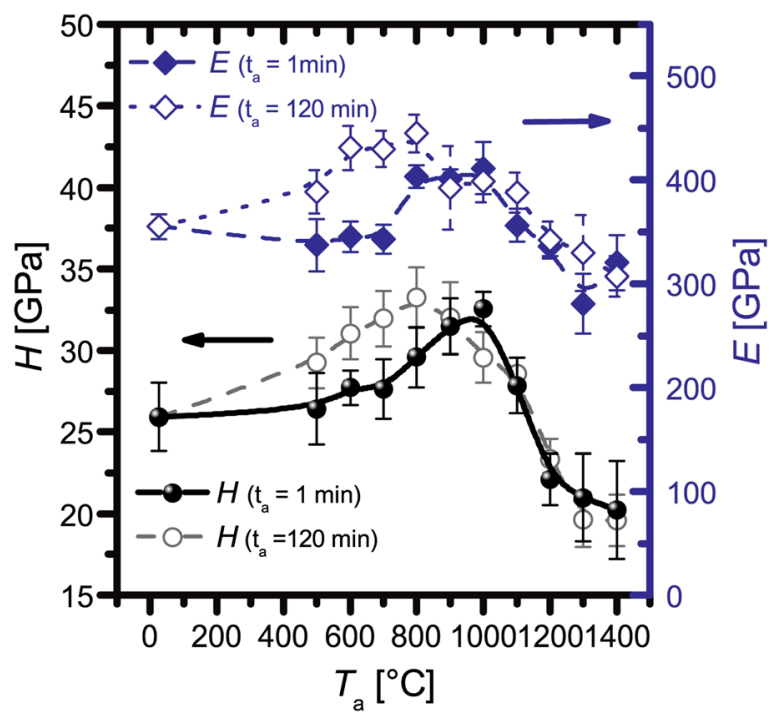

FIG. 2. (Color online) Hardness $(H)$ and indentation modulus $(E)$ of $\mathrm{Ti}_{0.46} \mathrm{Al}_{0.54} \mathrm{~N}$ as a function of $T_{\mathrm{a}}$ for $t_{\mathrm{a}}=1$ min (full symbols) and $t_{\mathrm{a}}=120$ min (open symbols). increase of $E$, which then decreases again due to the formation of w-AlN in the overaging regime.

In order to effectively eliminate substrate influence, for a further quantitative study by means of Williamson-Hall analysis, ${ }^{24}$ only the powder XRD-data were evaluated for all annealing treatments. To give an overview of the phase development between the samples annealed for 1 and $120 \mathrm{~min}$, quasi twodimensional plots of the recorded XRD-patterns are given in Figs. 3(a) and 3(b), respectively, where the X-ray intensities are illustrated by a corresponding color code. The XRD patterns were recorded in $100^{\circ} \mathrm{C}$ steps after annealing and are linearly interpolated. Significant peak broadening indicates phase separation of the single phase cubic matrix at temperatures below $1100^{\circ} \mathrm{C}$ for $t_{\mathrm{a}}=1 \mathrm{~min}$ [Fig. 3(a)] and $900^{\circ} \mathrm{C}$ for $t_{\mathrm{a}}=120 \mathrm{~min}$ [Fig. 3(b)]. The peak broadening of the cubic reflexes, as discussed above and in literature, ${ }^{8,14}$ results from spinodal decomposition, where TiN- and AlN-rich domains are formed that have slightly different lattice parameters. Due to the diffuse nature of the domain boundaries ${ }^{10}$ no sharp signal of the two domains can be detected. For both annealing times it was found that w-AlN can be detected first with its $(10-10)$ peak at $\sim 33.2^{\circ}$ at $T_{\mathrm{a}}=1100^{\circ} \mathrm{C}$ for $t_{\mathrm{a}}=1 \min$ and $T_{\mathrm{a}}=900^{\circ} \mathrm{C}$ for $t_{\mathrm{a}}=120 \mathrm{~min}$, followed by higher indexed reflexes at higher $T_{\mathrm{a}}$. As a guide for interpretation, a solid orange line connects the signals at $2 \%$ of the highest detected intensity, highlighting the discussed XRD-peak broadening and the advent of the (10-10) reflex for w-AlN. By increasing the annealing time from 1 to $120 \mathrm{~min}$, the formation of w-AlN is shifted to $\sim 200^{\circ} \mathrm{C}$ lower temperatures. This indicates a strong diffusion-driven and hence time-dependent decomposition behavior at different temperatures, confirming earlier predictions. ${ }^{12}$

The development of the lattice parameters as a function of $T_{\mathrm{a}}$ and $t_{\mathrm{a}}$ is highlighted in Fig. 4. The cubic lattice parameter $a_{\mathrm{c}}$ was calculated from the main XRD response at $\sim 43^{\circ}$, (002) peak in c- $\mathrm{Ti}_{1-x} \mathrm{Al}_{x} \mathrm{~N}$. With increasing $T_{\mathrm{a}}$ the cubic lattice parameter decreases for the $1 \mathrm{~min}$ and $120 \mathrm{~min}$ annealing to a minimum of $\sim 4.16 \AA$ at $T_{\mathrm{a}}=1000^{\circ} \mathrm{C}$ and $800^{\circ} \mathrm{C}$, respectively, coinciding with the maximum in $H$ and $E$, and then increases to meet the value of $4.24 \AA$ for TiN; see Fig. 4. Similarly, the hexagonal lattice parameters $a_{\mathrm{w}}$ and $c_{\mathrm{w}}$ were determined from w-AlN (10-10) and (0002) peaks, respectively. At high $T_{\mathrm{a}}$, where w-AlN can be detected, both $a_{\mathrm{w}}$ and $c_{\mathrm{w}}$ deviate significantly from the stoichiometric values of 3.11 and $4.98 \AA$ for w-AlN ${ }^{31}$ (see Fig. 4).

The impact of this structural development on the microstrains $(\varepsilon)$ of the cubic phase is given in Fig. 5(a). Please note that these strains refer only to intrinsic stresses of second and third order, as a result of the incorporation of defects $^{32}$ and initial chemical fluctuations of Ti- and Al-concentrations ${ }^{10}$ because the measurements are conducted on free-standing film material (see Sec. II B). Therefore, only stresses between individual grains or columns (second order) and within these microstructural features (third order) are responsible for the observed microstrains. The initial strain of the $\mathrm{c}-\mathrm{Ti}_{0.46} \mathrm{Al}_{0.54} \mathrm{~N}$ solid solution remains at $\sim 0.8 \%$ with annealing up to the deposition temperature of $500^{\circ} \mathrm{C}$. The samples annealed for $1 \mathrm{~min}$ at $T_{\mathrm{a}}$ exhibit a moderate increase of $\epsilon$ with $T_{\mathrm{a}}$, which suggests an increase of coherency strain as only isostructural decomposition is expected in this 
(a) $t_{\mathrm{a}}=1 \mathrm{~min}$

(b) $t_{\mathrm{a}}=120 \mathrm{~min}$

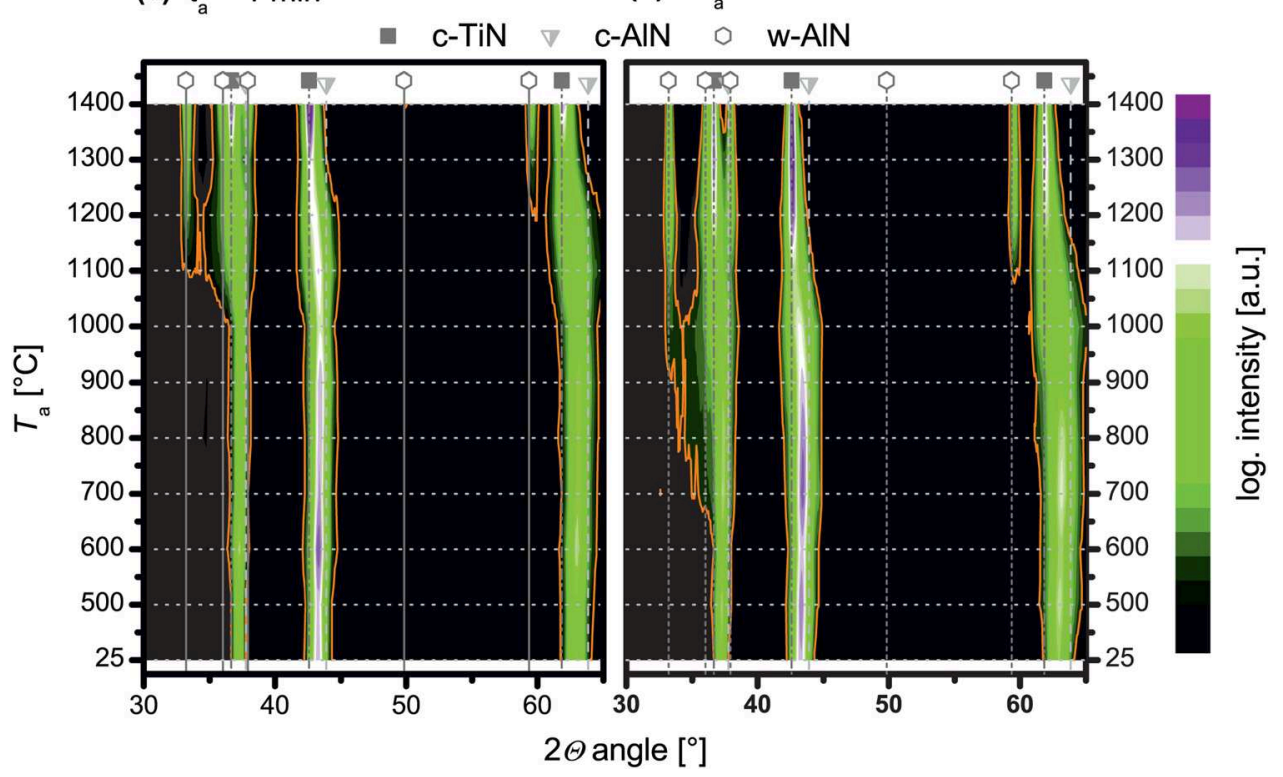

FIG. 3. (Color online) Quasi-two dimensional XRD-plot of $\mathrm{Ti}_{0.46} \mathrm{Al}_{0.54} \mathrm{~N}$ powder annealed to $T_{\mathrm{a}}$ for $t_{\mathrm{a}}=1 \min$ (a) and $t_{\mathrm{a}}=120 \mathrm{~min}(\mathrm{~b})$. Note that the logarithmic intensity corresponds to the color code in the scale bar. The orange line highlights the $2 \%$ threshold value of the normalized intensity.

temperature range; compare to Figs. 1 and 3. The atomic assembly due to isostructural decomposition is schematically presented in Fig. 5(b). For the samples annealed for $120 \mathrm{~min}$ at $T_{\mathrm{a}}$ there is a more pronounced increase of with $T_{\mathrm{a}}$, indicating the strong impact of $t_{\mathrm{a}}$ on the decomposition kinetics. The strain values after annealing for $t_{\mathrm{a}}=1$ and $120 \mathrm{~min}$ at $T_{\mathrm{a}}=1000$ and $800^{\circ} \mathrm{C}$, are 1.31 and $1.33 \%$, respectively. This

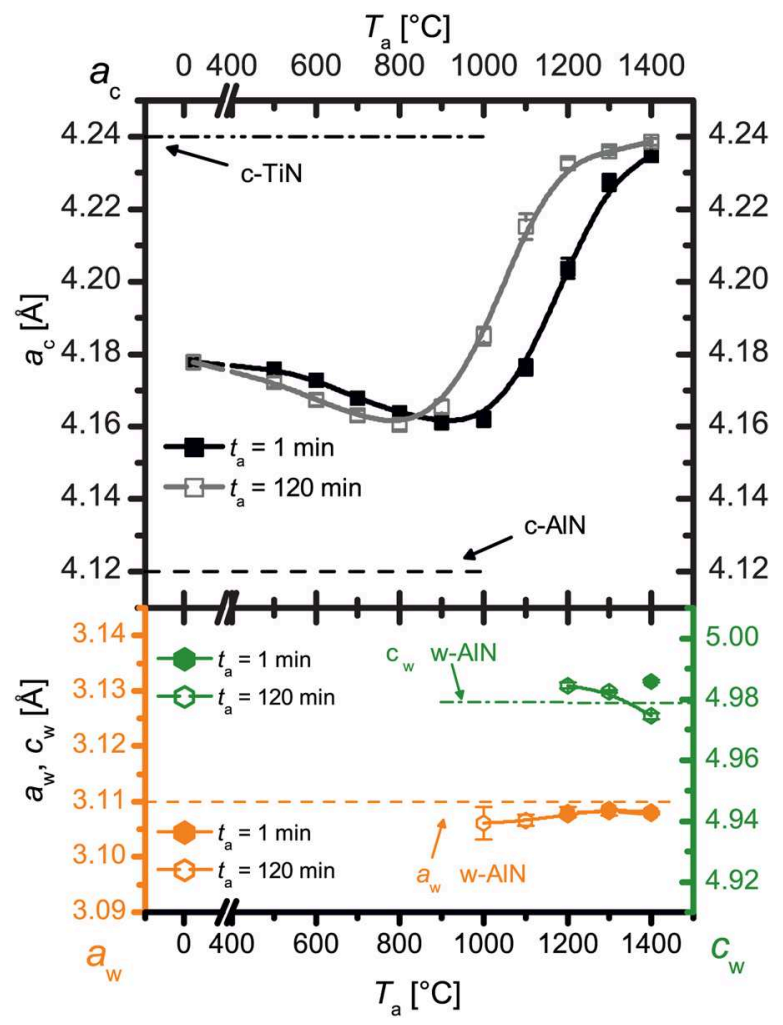

FIG. 4. (Color online) Lattice parameters of the cubic ( $a_{\mathrm{c}}-$ above) and the wurtzite phase ( $a_{\mathrm{w}}, c_{\mathrm{w}}$ - below) as obtained from powder X-ray diffraction. Full and open symbols refer to the values obtained after annealing for $t_{\mathrm{a}}=1$ min and $120 \mathrm{~min}$, respectively. Note that the error bars are only visible when they are not smaller than the symbol size. means a strain increase of $\sim 60 \%$ compared to the as deposited value, where the hardness is at its maximum of $32.5 \pm 1.2 \mathrm{GPa}\left(t_{\mathrm{a}}=1 \mathrm{~min}\right)$ and $33.3 \pm 1.8 \mathrm{GPa}\left(t_{\mathrm{a}}=120\right.$ min), compare to Fig. 2, and the cubic lattice parameter is at its minimum of $\sim 4.16 \AA$, see Fig. 4 .

The decrease of $a_{\mathrm{c}}$ is thus not simply related to the recovery of built-in defects, but rather an effect of isostructural decomposition and the concomitant development of microstrains, as schematically shown in Fig. 5(b) for the single phase regime. The maximum microstrain of 1.75 and $2.00 \%$ for $t_{\mathrm{a}}=1$ and $120 \mathrm{~min}$ is observed at $T_{\mathrm{a}}=1100$ and $900^{\circ} \mathrm{C}$, respectively, and consequently $100^{\circ} \mathrm{C}$ above the temperature for peak hardness and minimum cubic lattice parameter. Here, already small fractions of w-AlN with distorted lattice parameters $a_{\mathrm{w}}$ and $c_{\mathrm{w}}$ can be detected, as evident in a comparison between Fig. 3 and Fig. 4. Within the dual phase regime, $\varepsilon$ declines more strongly in the samples annealed for $t_{\mathrm{a}}=1 \mathrm{~min}$ compared to those annealed for $t_{\mathrm{a}}=120$ min which exhibit a smaller strain decrease between 900 and $1100^{\circ} \mathrm{C}$ before $\varepsilon$ strongly decreases at higher $T_{\mathrm{a}}$. This strain development is in excellent agreement with the observed hardness values, which decrease more slowly for the samples annealed for $t_{\mathrm{a}}=120 \mathrm{~min}$ in the temperature range $\left(900^{\circ} \mathrm{C}<T_{\mathrm{a}}<1100^{\circ} \mathrm{C}\right)$; compare Fig. 2. Thus almost similar hardness values were obtained for $t_{\mathrm{a}}=1$ and $120 \mathrm{~min}$ at $T_{\mathrm{a}}=900$ and $1100^{\circ} \mathrm{C}$, although stemming from two significantly different decomposition states with respect to strain and structure (e.g., before and after precipitation of w-AlN). A further increase of $T_{\mathrm{a}}$ (as soon as $\mathrm{W}-\mathrm{AlN}$ precipitates) results in coarsening of the dual phase structure and a concomitant strain decrease for both $t_{\mathrm{a}}$, as shown schematically in Fig. 5(c) and described in the following section.

\section{B. Three-dimensional-morphology and chemical assembly}

For additional chemical information at the atomic scale during the decomposition process, atom probe measurements 
(a)
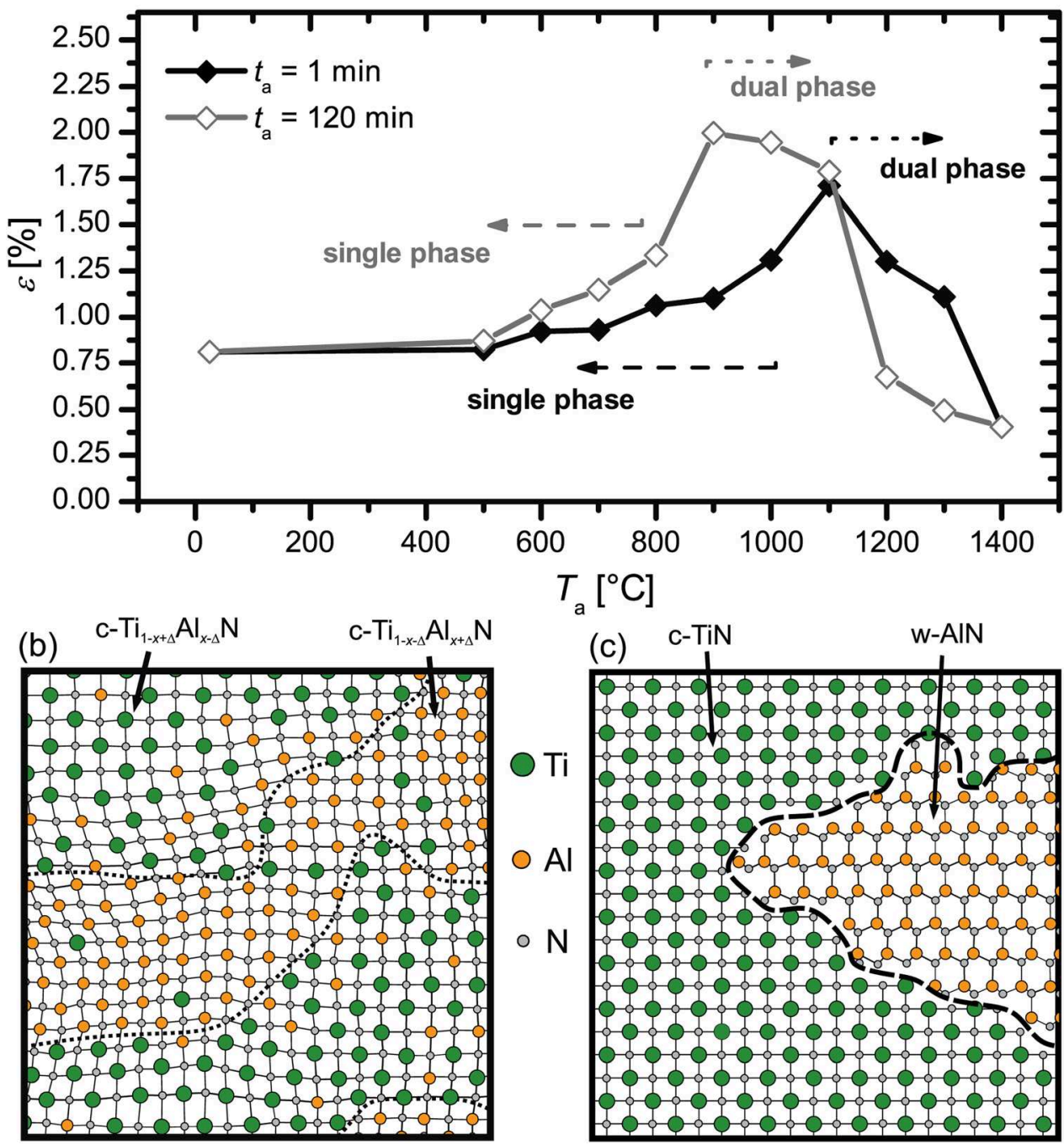

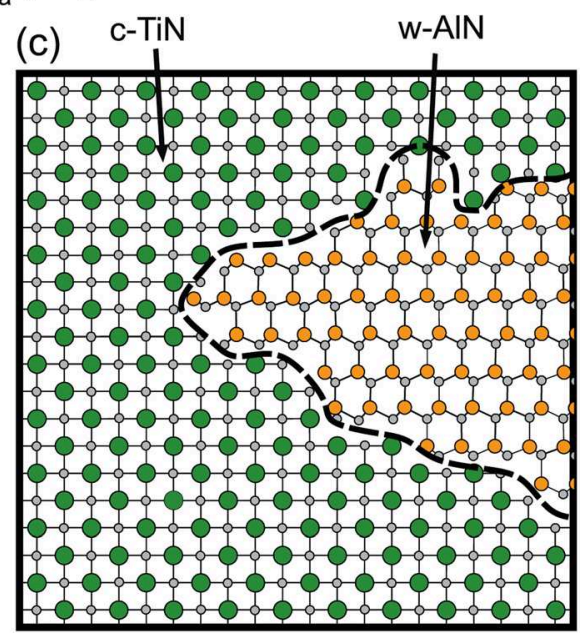

FIG. 5. (Color online) (a) Microstrain, $\epsilon$, obtained from the powder samples after annealing at $T_{\mathrm{a}}$ for $t_{\mathrm{a}}=1 \mathrm{~min}$ (black full symbols) and $t_{\mathrm{a}}=120 \mathrm{~min}$ (gray open symbols) using the WilliamsonHall-method. ${ }^{24}$ Schematic illustration of the atomic assembly for (b) the isostructural decomposition into c-TiN- and cAlN-enriched domains which causes the strain increase in the single phase regime, and (c) the dual phase structure at higher $T_{\mathrm{a}}$ resulting in strain decrease due to grain growth. were performed on samples annealed at $900{ }^{\circ} \mathrm{C}$ for $t_{\mathrm{a}}=1$ and $120 \mathrm{~min}$. These conditions were chosen, as they represent samples that are $100{ }^{\circ} \mathrm{C}$ below (for $t_{\mathrm{a}}=1 \mathrm{~min}$ ) and $100^{\circ} \mathrm{C}$ above (for $t_{\mathrm{a}}=120 \mathrm{~min}$ ) those with observed peak hardness. Additionally, a sample in the as deposited state (for reference) and a sample annealed at $T_{\mathrm{a}}=1350{ }^{\circ} \mathrm{C}$ for $1 \mathrm{~min}$ are investigated. The latter represents the decomposed state of the film composed of $\mathrm{c}-\mathrm{TiN}$ and $\mathrm{W}-\mathrm{AlN}$ as shown in Figs. 1 and 3. Statistical 3D-APT data treatment in combination with 2 D-concentration plots and isoconcentration surfaces were selected to graphically portray the morphological evolution of the $\mathrm{c}-\mathrm{Ti}_{0.46} \mathrm{Al}_{0.54} \mathrm{~N}$ films under thermal load.

The datasets were evaluated according to a maximum likelihood method, using the Langer-Bar on-Miller (LBM) treatment, ${ }^{33,34}$ which approximates the probability distributions of the decomposing phases as two Gaussian distributions of equal width, $\sigma$, located at respective concentrations $\mu_{1}$ and $\mu_{2}$. Thereby, the magnitude of the average local chemical fluctuations of the metallic sublattice can be expressed as the difference between the two Gaussians, $\mu_{2}-\mu_{1}$, as shown in Fig. 6(a). Since the magnitude of compositions in APT-data is extremely sensitive to the selected block size ${ }^{35}$ the LBM-treatment was carried out for different block sizes as presented in Fig. 6(a). Too small block sizes lead to statistical noise in the calculation and tend to overestimate the magnitude of $\mu_{2}-\mu_{1}$, reflected by a decreasing slope with increasing block size up to $\sim 100$ atoms/block. This regime is followed by block sizes of the same order as the chemical composition before too large block sizes smooth out the real chemical fluctuations ${ }^{33}$ and $\mu_{2}-\mu_{1}$ rapidly increases again. It can be seen that the difference in chemical composition $\left(\mu_{2}-\mu_{1}\right)$ of the samples in the as deposited and annealed state reaches a first plateau at a block size of $\sim 100$ atoms/block. Consequently, this regime was chosen for the determination of the LBM statistics, which are presented in Table I.

A comparison of the observed frequency distribution with a binomial distribution and the LBM-model is presented for the Al-ions in Fig. 6(b). The presentation of the obtained values for $\mathrm{Al}$ is favorable to $\mathrm{Ti}$ due to the slightly higher $\mathrm{Al}-$ content in the film, although the results for $\mathrm{Ti}$ are qualitatively similar. For all samples a significant deviation from a random solid solution, usually described as a binomial distribution, is visible and the LBM-method gives the best 


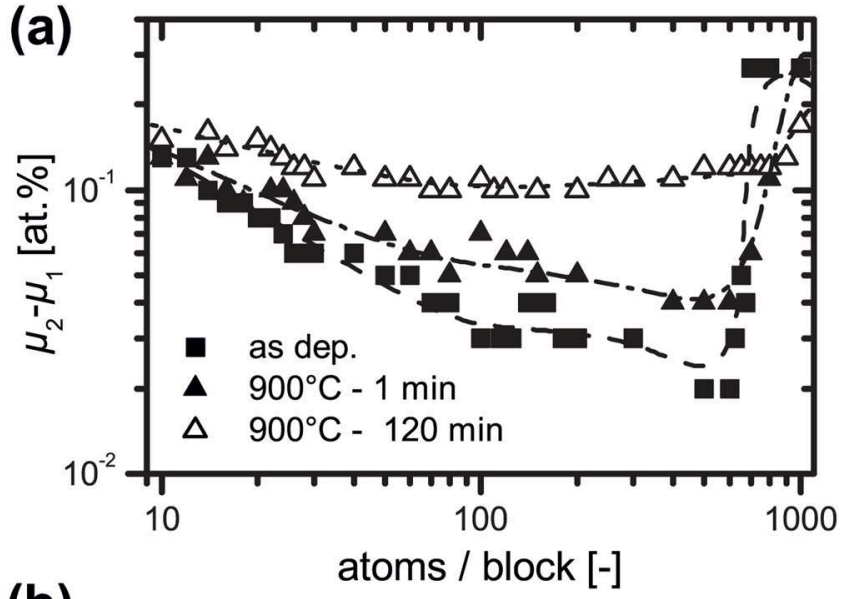

(b)

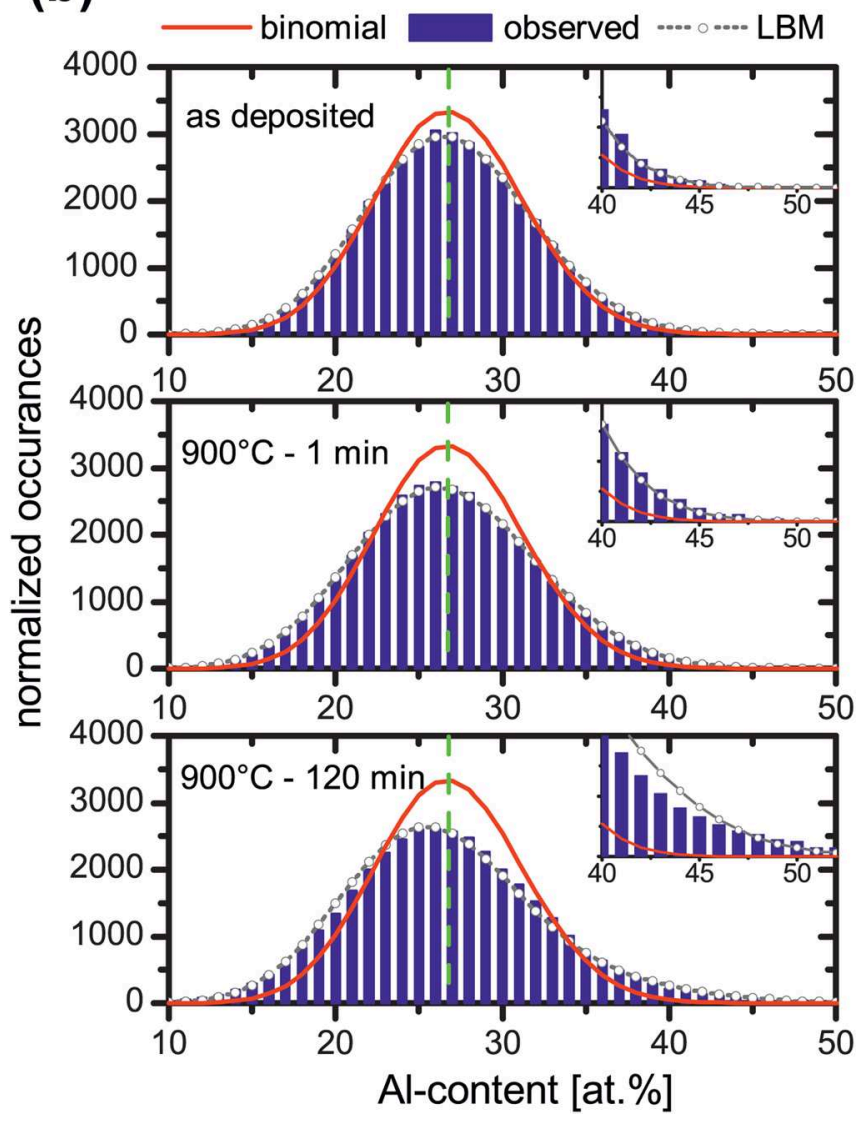

FIG. 6. (Color online) (a) The difference of the two gaussians $\mu_{2}-\mu_{1}$, reflecting the chemical compositions of the respective TiN- or AlN-enriched domains, as obtained from the Langer-Bar on-Miller treatment of the 3DAPT data as a function of block size. (b) Frequency distributions of the Al concentration for the as deposited (top) and annealed to $T_{\mathrm{a}}=900{ }^{\circ} \mathrm{C}$ for $t_{\mathrm{a}}=1 \mathrm{~min}$ (middle) and $120 \mathrm{~min}$ (bottom) state. The inserts present a magnification of the Al-rich part of the distribution. The green dashed line indicates the average $\mathrm{Al}$ composition of 26.5 at. $\%$.

approximation for the as deposited state. In addition to an increasing width of the distribution, indicating phase separation, the samples annealed for $t_{\mathrm{a}}=1$ and $120 \mathrm{~min}$ at $T_{\mathrm{a}}=900^{\circ} \mathrm{C}$ exhibit an increasing asymmetry, which is more pronounced for the $120 \mathrm{~min}$ sample. The high $\chi^{2}$ value for $T_{\mathrm{a}}=900^{\circ} \mathrm{C}$ and $t_{\mathrm{a}}=120 \mathrm{~min}$ (Table I) suggests that the LBM-model becomes insufficient to describe the present decomposition state. These results are consistent with the
TABLE I. Parameters of the LBM-fits to the frequency distributions shown in Fig. 6.

\begin{tabular}{lcccc}
\hline \hline & & as deposited & $900^{\circ} \mathrm{C}-1$ min & $900^{\circ} \mathrm{C}-120 \mathrm{~min}$ \\
\hline$\mu_{1}$ & {$[\%]$} & 25.9 & 25.3 & 29.0 \\
$\mu_{2}$ & {$[\%]$} & 28.9 & 32.3 & 41.0 \\
$\sigma$ & {$[\%]$} & 2.0 & 4.0 & 4.0 \\
$\chi^{2}$ & {$[-]$} & 45.9 & 90.1 & 1074 \\
d.o.f. & {$[-]$} & 35 & 41 & 50 \\
\hline \hline
\end{tabular}

experimentally observed asymmetric peak development of the cubic reflexes in the X-ray diffraction investigations. The small inserts in each frequency distribution highlight the deviation from the binomial (red solid line) and LBM-model (gray dashed line with circles) at high Al-concentrations. The results suggest the presence of stoichiometric AlN (Alcontent of 50 at.\%) for the sample annealed at $900^{\circ} \mathrm{C}$ for $120 \mathrm{~min}$.

The graphical presentation of the investigated samples, shown in Figs. 7(a)-7(d), was performed by isosurfaces ${ }^{36,37}$ at Al-concentrations of 28.5 at.\% (as deposited), 29.5 at.\% $\left(900^{\circ} \mathrm{C}\right.$ for 1 and $\left.120 \mathrm{~min}\right)$, and 46.5 at. $\%\left(1350^{\circ} \mathrm{C}\right.$ for 1 $\mathrm{min})$, respectively. These isoconcentration values are 2,3 , and 20 at.\% above the 26.5 at.\% average Al-concentration, in order to graphically emphasize the increasing local elemental fluctuations and phase separation with $T_{\mathrm{a}}$ and $t_{\mathrm{a}}$. The two-dimensional concentration plots represent the respective $\mathrm{Al}$ and $\mathrm{Ti}$ concentrations, projected toward the $y$-direction of the highlighted yellow boxes $(50 \times 2 \times 80 \mathrm{~nm})$ in the center of the tips. Due to the sample preparation technique, the field evaporation (measurement direction $z$ ) of the shown tips was perpendicular to the thin film growth direction ( $y$-axis) as described in Ref. 20. Hence, the 2 D-plots give plan-view information about the local element distribution across column boundaries.

Already in the as deposited state, local elemental fluctuations of $\mathrm{Al}$ and $\mathrm{Ti}$ ions in opposite directions were detected [Fig. 7(a)], confirming the deviation from an ideal random element distribution as mentioned above and presented in Ref. 10. Note the different scales for the $\mathrm{Al}$ and Ti concentrations in the different annealing states enhancing the color contrast of the respective decomposing domains. After annealing at $1350{ }^{\circ} \mathrm{C}$ for $1 \mathrm{~min}$, the formation of almost stoichiometric TiN and AlN can be confirmed by 3D-APT [see Fig. 7(d)]. Only small fractions of $\mathrm{Al}$ or $\mathrm{Ti}$ ions can be detected within the coarsened grains of the opposite species.

Annealing at $900^{\circ} \mathrm{C}$ for $1 \mathrm{~min}$ [see Fig. 7(b)] leads to an increasing compositional amplitude and the formation of TiNand AlN-enriched domains, spanning an interconnected 3Dnetwork compared to the as deposited state reported earlier. ${ }^{10}$ Although an increasing intensity of the compositional oscillations throughout the whole volume can be found, a stronger Al-enrichment can be detected at grain boundaries, highlighted by the red arrow. The development of a 3D-interconnected structure of c- $\mathrm{Ti}_{1-x-\Delta} \mathrm{Al}_{x+\Delta} \mathrm{N}$ and c- $\mathrm{Ti}_{1-x+\Delta} \mathrm{Al}_{x-\Delta} \mathrm{N}$ is a result of the spinodal decomposition process and therefore coincides with the structural investigations as described 
(a)

as dep.

Al-iso:

28.5 at. $\%$
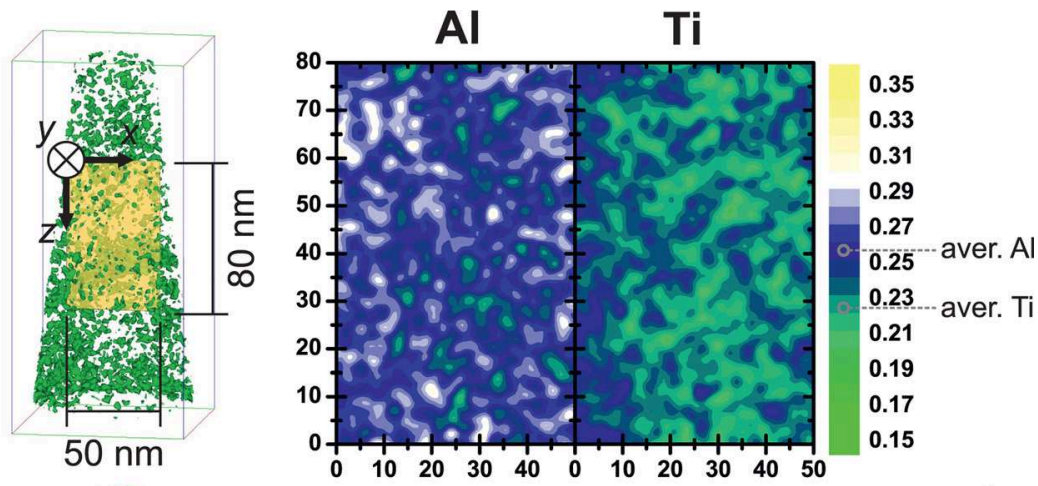

(b)

$\begin{aligned} T_{\mathrm{a}} & =900{ }^{\circ} \mathrm{C} \\ t & =1 \mathrm{~min}\end{aligned}$

Al-iso:

29.5 at. $\%$

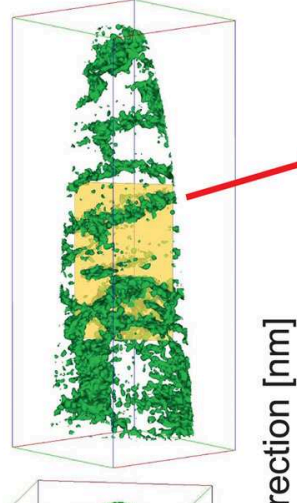

(c)

$T_{\mathrm{a}}=900^{\circ} \mathrm{C}$

$t_{\mathrm{a}}=120 \mathrm{~min}$

Al-iso:

29.5 at. $\%$

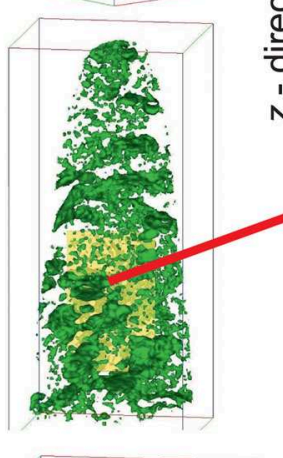

(d)

$T_{\mathrm{a}}=1350^{\circ} \mathrm{C}$

$t_{\mathrm{a}}=1 \mathrm{~min}$

Al-iso:

46.5 at. $\%$

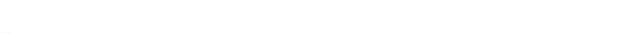

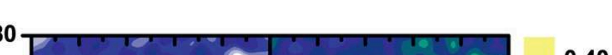

을

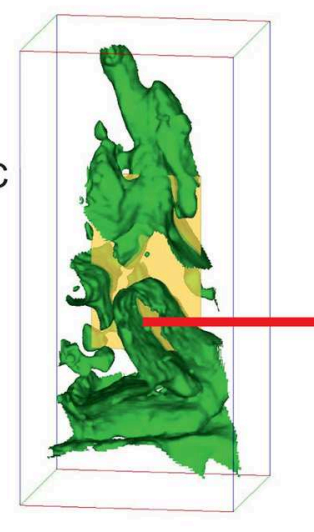

FIG. 7. (Color online) Isoconcentration surfaces for $\mathrm{Al}$ contents drawn at the given threshold values for the as deposited state (a), after annealing at $900{ }^{\circ} \mathrm{C}$ for $1 \mathrm{~min}(\mathrm{~b})$ and $120 \mathrm{~min}(\mathrm{c})$ and after annealing at $1350{ }^{\circ} \mathrm{C}$ for $1 \mathrm{~min}$ (d). The $2 \mathrm{D}$-concentration plots on the right side present the respective element distribution of $\mathrm{Al}$ or Ti calculated in the $y$-direction (initial growth direction) of the box shown in the center of the tips. The arrows indicate regions with highest $\mathrm{Al}$ concentration gradients identified as column boundaries, see also Fig. 9 .

above. Using electron energy loss spectroscopy (EELS) Knutsson et al. observed a qualitatively similar element distribution in arc-evaporated $\mathrm{TiN}^{-} \mathrm{Ti}_{0.34} \mathrm{Al}_{0.66} \mathrm{~N}$ multilayer coatings after annealing to $900^{\circ} \mathrm{C} .^{38,39}$ The locally higher compositional amplitude at former grain boundaries is likely to originate from the higher diffusivity as compared to the grain interior. Also a Kirkendall-like behavior, due to the higher diffusivity of $\mathrm{Al}$ compared to $\mathrm{Ti}$, can contribute to this effect as proposed by Johnson et al. for $\mathrm{Ti}_{0.34} \mathrm{Al}_{0.66} \mathrm{~N}$ after annealing at $900{ }^{\circ} \mathrm{C}^{26}$ The sample annealed at $900{ }^{\circ} \mathrm{C}$ for 120 min [Fig. 7(c)] indicates that the compositional mismatch of the TiN- and AlN-enriched domains within the grains significantly increased compared to samples annealed only for 1 $\mathrm{min}$. Also here the highest $\mathrm{Al}$ contents were found at the grain boundaries (red arrow). At this annealing stage, the AlN-rich domains are clearly elongated along the growth direction of the film and locally reach an $\mathrm{Al}$ concentration of $\sim 50$ at.\%; compare also Fig. 6(b). Theoretical and experimental 


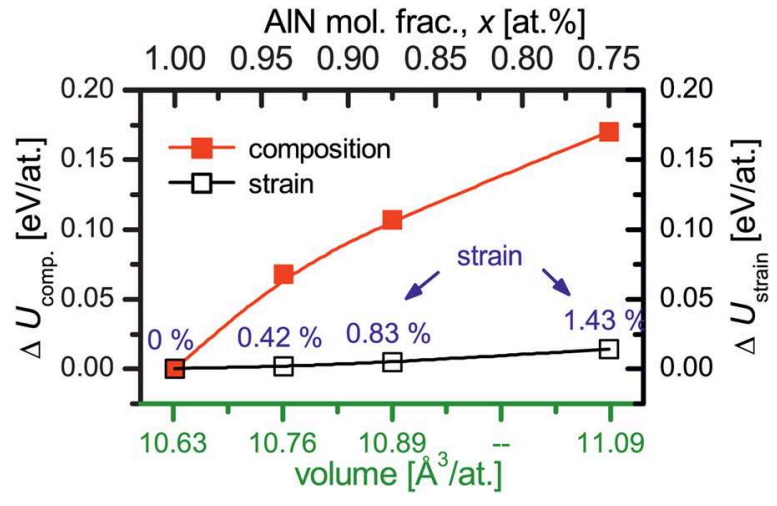

FIG. 8. (Color online) Ab initio results in the change of the total internal energy of w-AlN due to Ti-impurities ( $\Delta U_{\text {comp. }}-$ red full symbols) as a function of Al-mole fraction $(x)$ and the corresponding increase of the atomic volume. The total internal energy changes due to strain $\left(\Delta U_{\text {strain }}-\right.$ open black symbols) of stoichiometric w-AlN distorted to the same volumes reaches a significantly lower increase in internal energy and is thus suggested to be energetically favorable.

investigations on $\mathrm{Ti}_{0.50} \mathrm{Al}_{0.50} \mathrm{~N}$ thin films ${ }^{40,41}$ suggest a different growth behavior of the TiN- or AlN-rich domains in the growth direction and perpendicular to it due to the strong dependence of the mixing enthalpy on the local atomic ordering and strain effects. ${ }^{42} \mathrm{~A}$ further argument takes into account the generation and reduction of internal stresses during decomposition which stems from a strong orientation relationship between the decomposing counterparts. ${ }^{43}$
In order to determine the impact of strain or Ti-impurities on the total internal energy of w-AlN, ab initio calculations were performed. Figure 8 shows that the change in internal energy, $\Delta U_{\text {comp. }}$, of w-AlN strongly increases to $0.17 \mathrm{eV}^{-1}$ if $\mathrm{Ti}$ atoms substitute $\mathrm{Al}$ in w-AlN (red full squares) to obtain a $4.3 \%$ larger cell size. If, on the other hand, stoichiometric wAlN is strained by $1.43 \%$ to reach a comparable cell size, the change in internal energy, $\Delta U_{\text {strain }}$, (black open squares) is much smaller $\left(\sim 0.015 \mathrm{eV} \mathrm{at}^{-1}\right)$, see Fig. 8. This result is in general agreement with the limited solubility of Ti in w-AlN and suggests that the lattice parameter deviation of w-AlN during precipitation, as obtained from our experiments (Figs. 4 and 5), is mainly caused by strain rather than chemical variation.

More detailed investigations of the atomic arrangement at the grain boundaries are made using TEM. Figure 9(a) shows a bright-field (BF) plan view image of the coating annealed at $900^{\circ} \mathrm{C}$ for $120 \mathrm{~min}$. The insert shows the corresponding selected area electron diffraction (SAED) pattern, indicating strong c- $\mathrm{Ti}_{1-x+\Delta} \mathrm{Al}_{x-\Delta} \mathrm{N}$ reflexes and only little intensity of the w-AlN phase, in line with the X-ray investigations. The corresponding dark-field image, highlighting regions obtained from the w-AlN (10-10) reflex indicated in the SAED pattern, is shown in Fig. 9(b). Regions corresponding to the w-AIN phase are especially visible at the grain boundaries. The HR-TEM image, Fig. 9(c), from the area indicated with a rectangle in the dark-field image [Fig. 9(b)] emphasizes the presence of
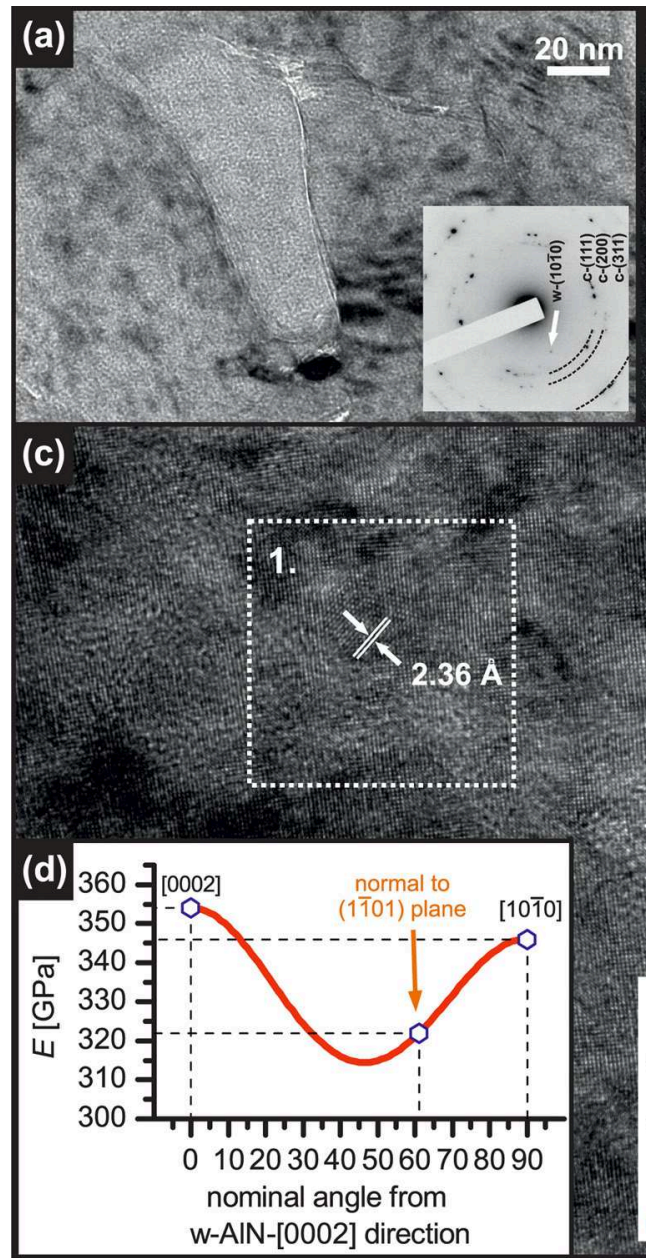
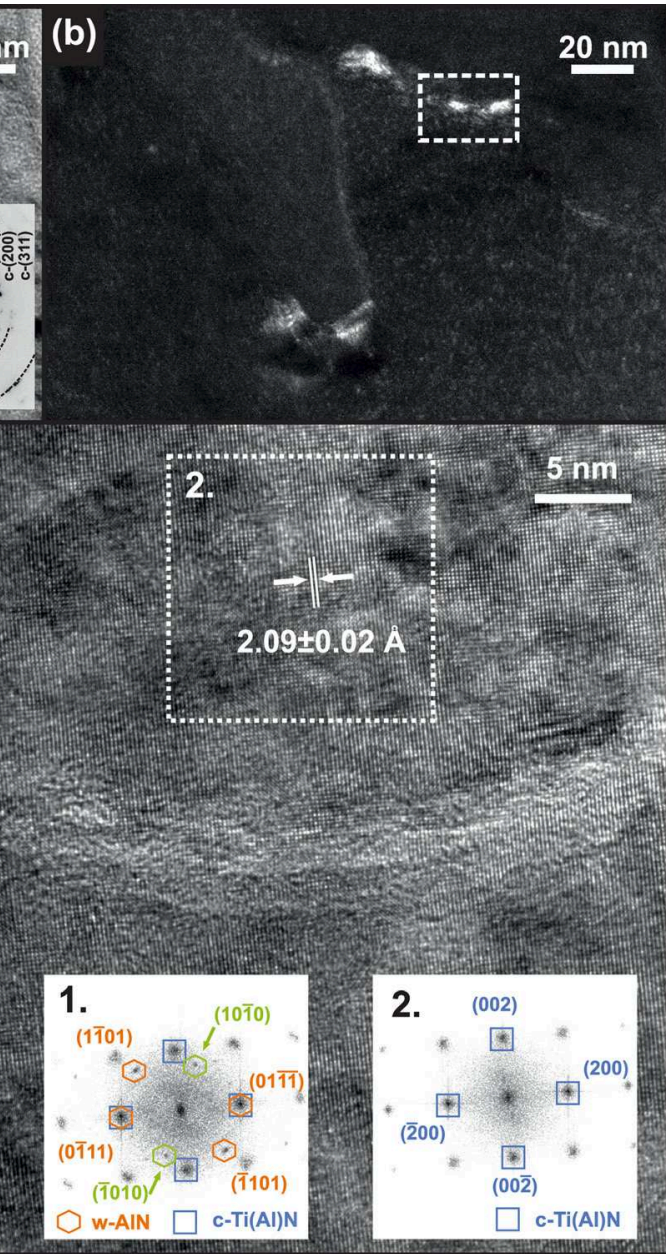

FIG. 9. (Color online) (a) Plan-view BF-TEM micrograph of the $\mathrm{Ti}_{0.46} \mathrm{Al}_{0.54} \mathrm{~N}$ thin film annealed to 900 ${ }^{\circ} \mathrm{C}$ for $120 \mathrm{~min}$, the insert shows a SAED pattern of this region. (b) Dark field TEM image from the wurtzite reflex indicated in the SAED pattern. (c) HR-TEM image of the highlighted region from (b) showing w-AlN at the grain boundaries. The FFT inserts were obtained from the indicated regions 1 and 2, respectively. (d) The elastic anisotropy of w-AlN shown for the change of $E$-modulus with respect to the $[0002]_{\text {w-AIN }}$ direction. Note that [0002] and $[10-10]$ directions refer to a deformation along the c- and a-axis of the wAlN, respectively. 
semicoherent and incoherent interfaces between the w-AlN precipitates and the surrounding cubic $\mathrm{Ti}_{1-\mathrm{x}+}+\mathrm{Al}_{\mathrm{x}-} \mathrm{N}$ matrix. The measured lattice constant $a_{\mathrm{c}}$ of the c- $\mathrm{Ti}_{1-x+\Delta} \mathrm{Al}_{x-\Delta} \mathrm{N}$ matrix varies between $4.18 \AA$ and $4.21 \AA$, depending on the area of investigation. This modulation corresponds to the local Al-fluctuations in agreement with literature. ${ }^{44}$ Fast Fourier transformation (FFT) of region 1, corresponding to the w-AlN precipitate, exhibits three sets of additional reflexes compared to the solely cubic reflexes of region 2 [see inserts in Fig. 9(c)]. Since the w-AlN precipitate is highly strained, the reflexes overlap with the cubic reflexes in one direction, indicating a partial coherency of the $(01-1-1)_{\mathrm{w}-\mathrm{AlN}} / /(002)_{\text {cubic }}$ planes, whereas the other two are in no orientation relationship with the surrounding matrix. Rafaja et al ${ }^{43}$ recently proposed an orientation relationship between $(11-1)_{\text {cubid }} /(0002)_{\mathrm{w}-\mathrm{AlN}}$ planes in as deposited nanocomposite $\mathrm{Ti}_{0.50} \mathrm{Al}_{0.50} \mathrm{~N}$ coatings, which exhibits the lowest mismatch between the two phases along the $[1-10]_{\text {cubicl }}$ / $[10-10]_{\mathrm{w}-\mathrm{AlN}}$ directions. However, the existence of the partial coherency also along other crystallographic orientations can be explained by the high distortion of the w-AlN in its initial precipitation stage, which has to compensate the $\sim 24 \%$ higher volume per formula unit of w-AlN compared to c-AlN.$^{45}$ Further, the elastic anisotropy of w-AIN, regarded as a function of the angle with respect to the [0002 $]_{\text {w-AlN }}$ direction, is shown in Fig. 9(d). The lower elastic modulus in a direction perpendicular to the $(01-1-1)_{\mathrm{w}-\mathrm{AlN}}$ plane therefore suggests the easier displacement of $(01-1-1)$ planes, compared to the $(10-10)_{\text {w-AlN }}$ planes, in agreement with the FFT of region 1 . The observed strain maximum in the cubic phase (see Fig. 5) therefore results from the w-AlN precipitation at this annealing state.

\section{Electrical resistivity}

The sheet resistivity of $\mathrm{Ti}_{1-x} \mathrm{Al}_{x} \mathrm{~N}$ coatings is known to strongly scale with the $\mathrm{Al}$ mole fraction, $x$, and the structure obtained after deposition. ${ }^{46} \mathrm{TiN}$ films exhibit an almost metallic

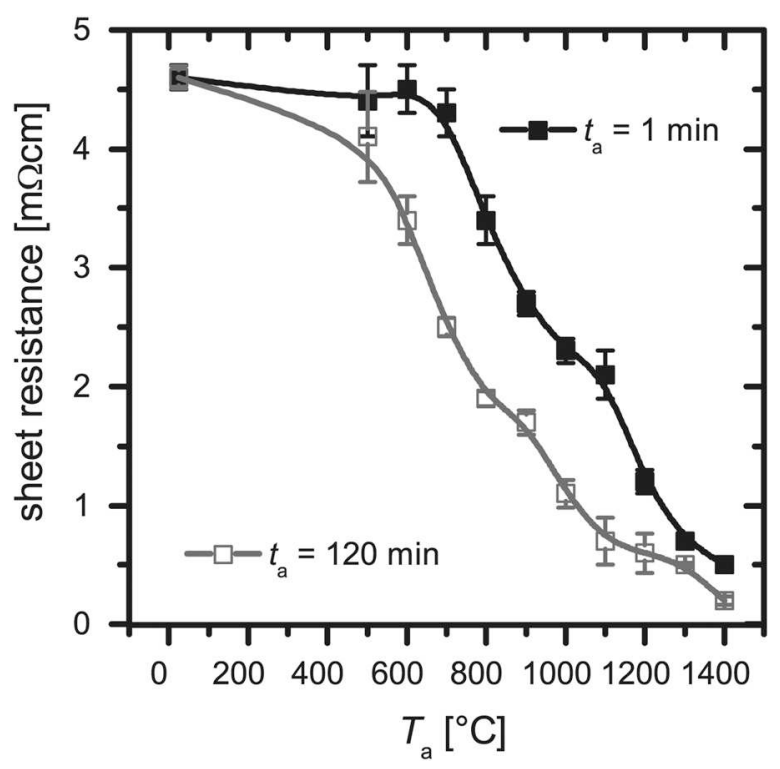

FIG. 10. Electrical resistivity of the $\mathrm{Ti}_{0.46} \mathrm{Al}_{0.54} \mathrm{~N}$ thin films measured after annealing at $T_{\mathrm{a}}$ and $\mathrm{t}_{\mathrm{a}}=1 \mathrm{~min}$ (black full symbols) and $120 \mathrm{~min}$ (gray open symbols). The evolution of sheet resistivity reflects the state of decomposition (compare Figs. 3 and 7). conduction behavior $\left(\sim 0.1 \mathrm{~m} \Omega \mathrm{cm}^{47}\right)$, while AlN films are semiconducting $\left(\sim 10^{13}\right.$ to $\left.10^{15} \mathrm{~m} \Omega \mathrm{cm}^{48}\right)$. Due to the thermally induced structural changes of $\mathrm{c}-\mathrm{Ti}_{0.46} \mathrm{Al}_{0.54} \mathrm{~N}$, the sheet resistivity decreases by 1 order of magnitude from $\sim 4.6 \mathrm{~m} \Omega \mathrm{cm}$ after deposition to $\sim 0.5 \mathrm{~m} \Omega \mathrm{cm}$ after annealing at $T_{\mathrm{a}}=1400^{\circ} \mathrm{C}$ for 1 $\mathrm{min}$ and $\sim 0.2 \mathrm{~m} \Omega \mathrm{cm}$ for $120 \mathrm{~min}$, respectively; see Fig. 10. As suggested above, the spinodal morphology of $\mathrm{c}-\mathrm{Ti}_{1-x+\Delta} \mathrm{Al}_{x-\Delta} \mathrm{N}$ and $\mathrm{c}-\mathrm{Ti}_{1-x-\Delta} \mathrm{Al}_{x+\Delta} \mathrm{N}$ domains, spanning an interconnected 3D-network throughout the volume of the film, opens a percolation pathway for charge transfer within the TiN-enriched domains (Fig. 7), being the electrically better conductive part of the composite. The state of decomposition is therefore reflected by the sheet resistivity, which goes along with the structural investigations as a function of $T_{\mathrm{a}}$ and $t_{\mathrm{a}}$.

\section{CONCLUSIONS}

The present work deals with the pathway of decomposition from single phase $\mathrm{c}-\mathrm{Ti}_{1-x} \mathrm{Al}_{x} \mathrm{~N}$ toward a dual phase structure composed of c-TiN and w-AlN, involving spinodal decomposition and subsequent precipitation and growth. We employ the model system $\mathrm{Ti}_{1-x} \mathrm{Al}_{x} \mathrm{~N}$ with an Al content of 54 at.\% at the metallic sublattice as this provides a huge decomposition driving force deep in the spinodal region, combined with a single phase cubic structure of large columnar grains after deposition. Three-dimensional atom probe tomographic studies of free standing coating samples annealed at $900^{\circ} \mathrm{C}$ show that the isostructural decomposition of $c-\mathrm{Ti}_{0.46} \mathrm{Al}_{0.54} \mathrm{~N}$ occurs within the entire coating volume. However, a higher AlN-enrichment was found at preferred diffusion pathways such as column or grain boundaries, while the extent of the local TiN- and AlN-enrichment in the grain interior is slightly retarded and becomes more pronounced with increasing annealing time from 1 to $120 \mathrm{~min}$. At this stage, first highly distorted w-AlN domains at the grain boundaries can be detected, as shown by HR-TEM investigations. Concomitant X-ray and nanoindentation experiments show that the hardness maximum of $32.5 \pm 1.2 \mathrm{GPa}\left(t_{\mathrm{a}}=1 \mathrm{~min}, T_{\mathrm{a}}=1000^{\circ} \mathrm{C}\right)$ and $33.3 \pm 1.8 \mathrm{GPa}\left(t_{\mathrm{a}}=120 \mathrm{~min}, T_{\mathrm{a}}=800^{\circ} \mathrm{C}\right)$ is achieved in the single phase regime where the relative microstrain shows an increase of $\sim 60 \%$. The results further demonstrate that the peak hardness is obtained at $\sim 100^{\circ} \mathrm{C}$ lower temperatures than the peak strain, which is observed during the early stages of w-AlN precipitation. The observed precipitation of highly strained w-AlN is supported by ab initio calculations, exhibiting a significantly higher change in internal energy due to residual Ti-impurities $(\Delta U \sim 0.17 \mathrm{eV}$ at $^{-1}$ ) than to strain $\left(\Delta U \sim 0.015 \mathrm{eV}\right.$ at $^{-1}$ ) for a comparable volume change of the cell by $\sim 4 \%$. The subsequent growth of w-AlN grains and out-diffusion of $\mathrm{Al}$ from the c-TiN-enriched domains with further increase of $T_{\mathrm{a}}$, results in a loss of coherency and causes a significant strain and hardness decrease. Moreover, the presented structural evolution goes in line with a reduction in electrical resistivity by 1 order of magnitude, which is related to the formation of a 3D-interconnected network of c-TiN-enriched domains (and finally c-TiN) with essentially lower electrical resistivity. 


\section{ACKNOWLEDGMENTS}

The work was supported by the START project (Project No. Y371) of the Austrian Science Fund (FWF). Further, RR wishes to acknowledge Dr. M. Schober for helpful discussions and Dr. Lawrence Whitmore for careful proof reading.

${ }^{1}$ S. PalDey and S. C. Deevi, Mater. Sci. Eng. A 342, 58 (2003).

${ }^{2}$ A. Hörling, L. Hultman, M. Odén, J. Sjölen, and L. Karlsson, Surf. Coat. Technol. 191, 384 (2005).

${ }^{3}$ M. Zhou, Y. Makino, M. Nose, and K. Nogi, Thin Solid Films 339, 203 (1999).

${ }^{4}$ A. Kimura, H. Hasegawa, K. Yamada, and T. Suzuki, J. Mater. Sci. Lett. 19, $601(2000)$

${ }^{5}$ P. Spencer, Int. J. Mater. Res. 92, 1145 (2001).

${ }^{6}$ H. Holleck, Surf. Coat. Technol. 36, 151 (1988).

${ }^{7}$ O. Knotek, M. Böhmer, and T. Leyendecker, J. Vac. Sci. Technol. A 4 , 2695 (1986).

${ }^{8}$ P. H. Mayrhofer, A. Hörling, L. Karlsson, J. Sjölen, T. Larsson, C. Mitterer, and L. Hultman, Appl. Phys. Lett. 83, 2049 (2003).

${ }^{9}$ P. H. Mayrhofer, L. Hultman, J. M. Schneider, P. Staron, and H. Clemens, Int. J. Mater. Res. 98, 1054 (2007).

${ }^{10}$ R. Rachbauer, E. Stergar, S. Massl, M. Moser, and P. H. Mayrhofer, Scr. Mater. 61, 725 (2009).

${ }^{11}$ A. E. Santana, A. Karimi, V. H. Derflinger, and A. Schütze, Tribol. Lett. 17, 689 (2004)

${ }^{12}$ P. H. Mayrhofer, F. D. Fischer, H. J. Böhm, C. Mitterer, and J. M. Schneider, Acta Mater. 55, 1441 (2007).

${ }^{13}$ P. H. Mayrhofer, D. Music, and J. M. Schneider, J. Appl. Phys. 100, 094906 (2006).

${ }^{14}$ A. Hörling, L. Hultman, M. Oden, J. Sjölen, and L. Karlsson, J. Vac. Sci. Technol. A 20, 1815 (2002)

${ }^{15}$ P. H. Mayrhofer, D. Music, and J. M. Schneider, Appl. Phys. Lett. 88, 071922 (2006).

${ }^{16}$ B. Alling, M. Odén, L. Hultman, and I. A. Abrikosov, Appl. Phys. Lett. 95, 181906 (2009).

${ }^{17}$ B. Alling, A. V. Ruban, A. Karimi, O. E. Peil, S. I. Simak, L. Hultman, and I. A. Abrikosov, Phys. Rev. B 75, 045123 (2007).

${ }^{18}$ R. F. Zhang and S. Veprek, Mater. Sci. Eng. A 448, 111 (2007).

${ }^{19}$ B. Alling, A. Karimi, and I. A. Abrikosov, Surf. Coat. Technol. 203, 883 (2008).

${ }^{20}$ R. Rachbauer, S. Massl, E. Stergar, P. Felfer, and P. H. Mayrhofer, Surf. Coat. Technol. 204, 1811 (2010).

${ }^{21}$ L. B. Valdes, Proc. I. R. E. 42, 420 (1954).

${ }^{22}$ F. M. Smits, Bell Syst. Tech. J. 37, 711 (1958).

${ }^{23}$ W. C. Oliver and G. M. Pharr, J. Mater. Res. 7, 1564 (1992).
${ }^{24}$ G. K. Williamson and W. H. Hall, Acta Metal. 1, 22 (1953).

${ }^{25}$ M. K. Miller, A. Cerezo, M. G. Hetherington, and G. D. W. Smith, Atom Probe Field Ion Microscopy (Oxford University Press, New York, 1996).

${ }^{26}$ L. J. S. Johnson, "Nanostructuring and Age Hardening in TiSiCN, ZrAlN and TiAlN Thin Films," Licentiate Thesis, Linköping University, 2010.

${ }^{27}$ D. Holec, R. Rachbauer, D. Kiener, P. D. Cherns, P. M. F. J. Costa, C. McAleese, P. H. Mayrhofer, and C. J. Humphreys, Phys. Rev. B 83, 165122 (2011).

${ }^{28}$ F. Tasnadi, I. A. Abrikosov, L. Rogström, J. Almer, M. P. Johansson, and M. Odén, Appl. Phys. Lett. 97, 231902 (2010).

${ }^{29}$ D. Holec, F. Rovere, P. H. Mayrhofer, and P. B. Barna, Scr. Mater. 62, 349 (2010).

${ }^{30}$ A. D. Porter and K. E. Easterling, Phase Transformations in Metals and Alloys (Van Nostrand Reinhold, UK, Wokingham, Berkshire, England, 1981).

${ }^{31}$ H. Schulz and K.H. Thiemann, Solid State Commun., 23, 815 (1977).

${ }^{32}$ D. Rafaja, A. Poklad, V. Klemm, G. Schreiber, D. Heger, M. Sìma, and M. Dopita, Thin Solid Films 514, 240 (2006).

${ }^{33}$ M. G. Hetherington, J. M. Hyde, M. K. Miller, and G. D. W. Smith, Surf. Sci. 246, 304 (1991)

${ }^{34}$ J. S. Langer, M. Bar-On, and H. D. Miller, Phys. Rev. A 11, 1417 (1975).

${ }^{35}$ M. G. Hetherington and M. K. Miller, Colloq. Phys. 8, 535 (1989).

${ }^{36}$ O. C. Hellman, J. B. Du Rivage, and D. N. Seidman, Ultramicroscopy 95, 199 (2003).

${ }^{37}$ M. K. Miller, J. M. Hyde, M. G. Hetherington, A. Cerezo, G. D. W. Smith, and C. M. Elliott, Acta Metall. Mater. 43, 3385 (1995).

${ }^{38}$ A. Knutsson, M. P. Johansson, P. O. A. Persson, L. Hultman, and M. Odén, Appl. Phys. Lett. 93, 143110 (2008).

${ }^{39}$ A. Knutsson, M. P. Johansson, L. Karlsson, and M. Odén, J. Appl. Phys. 108, $044312(2010)$

${ }^{40}$ B. Alling, T. Marten, I. A. Abrikosov, and A. Karimi, J. Appl. Phys. 102, 044314 (2007).

${ }^{41}$ M. Odén, L. Rogström, A. Knutsson, M. R. Terner, P. Hedström, J. Almer, and J. Ilavsky, Appl. Phys. Lett. 94, 053114 (2009).

${ }^{42}$ D. J. Seol, S. Y. Hu, Y. L. Li, J. Shen, K. H. Oh, and L. Q. Chen, Acta Mater. 51, 5173 (2003).

${ }^{43}$ D. Rafaja, C. Wüstefeld, C. Baehtz, V. Klemm, M. Dopita, M. Motylenko, C. Michotte, and M. Kathrein, Metall. Mater. Trans. A 42, 559 (2011).

${ }^{44}$ F. Adibi, I. Petrov, L. Hultman, U. Wahlströhm, T. Shimizu, D. McIntyre, J. E. Greene, and J. E. Sundgren, J. Appl. Phys. 69, 6437 (1991).

${ }^{45}$ N. E. Christensen and I. Gorczyca, Phys. Rev. B 47, 4307 (1993).

${ }^{46}$ T. Ikeda and H. Satoh, Thin Solid Films 195, 99 (1991).

${ }^{47}$ J. H. Huang, K. J. Yu, P. Sit, and G. P. Yu, Surf. Coat. Technol. 200, 4291 (2006).

${ }^{48}$ O. Elmazria, M. B. Assouar, P. Renard, and P. Alnot, Phys. Status Solidi A 196, $416(2003)$ 